\title{
Functional traits reveal environmental constraints on amphibian community assembly in a subtropical dry forest
}

Article in Austral Ecology · April 2018

DOI: 10.1111/aec.12607

\section{CITATIONS}

0

3 authors:

(20)

Julián Norberto Lescano

National Scientific and Technical Research Council 39 PUBLICATIONS 279 CITATIONS

SEE PROFILE

\section{READS}

112

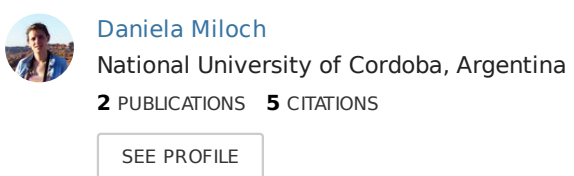

(3) Gerardo C. Leynaud

National University of Cordoba, Argentina

49 PUBLICATIONS 490 CITATIONS

SEE PROFILE

Some of the authors of this publication are also working on these related projects:

Conservation Biology of Freshwater Turtles and Tortoises from Argentina View project

The phylogeny of bothropoid pitvipers (Bothrops, Bothrocophias) View project 


\title{
Functional traits reveal environmental constraints on amphibian community assembly in a subtropical dry forest
}

\author{
JULIÁN N. LESCANO, ${ }^{1,2 \star ~(D) ~ D A N I E L A ~ M I L O C H ~}{ }^{1}$ AND GERARDO C. LEYNAUD ${ }^{1,2}$ \\ ${ }^{1}$ Facultad de Ciencias Exactas, Físicas y Naturales, Centro de Zoología Aplicada, Universidad Nacional de \\ Córdoba, Rondeau 798, (Email: lescanojul@gmail.com); ${ }^{2}$ Consejo Nacional de Investigaciones Científicas \\ y Técnicas (CONICET), Instituto de Diversidad y Ecología Animal (IDEA), Córdoba, Argentina
}

\begin{abstract}
The relationships between functional traits and environmental gradients are useful to identify different community assembly processes. In this work, we used an approach based on functional traits to analyse if changes in hydroperiod and tree covers of ponds are relevant for local amphibian community assembly processes. Ephemeral ponds with low vegetation cover are expected to impose constraints on different species with particular trait combinations and, therefore, to exhibit communities with lower functional diversity than more stable ponds with greater tree cover. Sampling was conducted in 39 temporary ponds located along vegetation and hydroperiod gradients in the most arid portion of the Chaco ecoregion. Seven functional traits were measured in each species present in the regional pool. Associations between these traits and environmental gradients were detected using multivariate ordination techniques and permutation test (RLQ and fourth-corner analyses respectively). Functional diversity indices were then calculated and related to variations in the environmental gradients. The results obtained allowed us to identify different sets of traits associated with hydroperiod and tree cover, suggesting that these environmental variables are relevant for structuring amphibian communities according to interspecific variations in functional traits from both, larval and adult stages. Contrary to our expectations, communities associated with more stable ponds and with greater tree cover exhibited lower functional diversity than expected by chance (and were the ponds with highest species richness). This result indicates that the reduction in relative importance of environmental restrictions imposed by a very short hydroperiod and the lack of tree cover, favours different species of the regional pool that are similar in several functional traits. Accordingly, communities associated with stable ponds with high tree cover exhibited high functional redundancy.
\end{abstract}

Key words: anurans, community structure, functional diversity, temporary ponds, trait syndromes.

\section{INTRODUCTION}

Understanding the mechanisms driving community assembly is a key challenge in ecology (Grime 2006; McGill et al. 2006). To disentangle these processes, ecologists have shifted from traditional approaches (i.e. measuring species composition and diversity) towards a functional trait-based approach (McGill et al. 2006; Webb et al. 2010; Mason \& De Bello 2013), since increasing evidence suggests that the relationships between functional traits (i.e. traits that indirectly impact individual fitness via their impacts on reproduction, growth and survival) and environmental factors have the potential to reveal community assembly processes and to enhance the predictive power of ecology (Díaz \& Cabido 2001; McGill et al. 2006; Violle et al. 2007; Mason et al. 2008).

Community assembly is often assumed as the outcome of two opposing forces: environmental filtering and competitive interactions. This environmental filtering vs. competition paradigm motivated a body of

${ }^{\star}$ Corresponding author.

Accepted for publication March 2018. research looking at the patterns of trait clustering among co-occurring species along environmental gradients. According to this rationale, environmental filtering should increase trait convergence and reduce functional diversity in the harshest (i.e. unproductive or disturbed) extremes of gradients, whereas trait overdispersion should be observed in more productive extremes due to niche divergence and limiting similarity (Weiher \& Keddy 1995; Cornwell et al. 2006; Mason et al. 2008; Maire et al. 2012). However, other bodies of work have shown contrasting responses of trait distribution patterns to environmental factors (Flynn et al. 2009; Mayfield \& Levine 2010; Weiher et al. 2011; Grime \& Pierce 2012; Spasojevic \& Suding 2012; Cadotte \& Tucker 2017). According to Mayfield and Levine (2010), high level of competition in productive environments could lead to both trait clustering and trait overdispersion, depending on the relative importance of differences in competitive ability or niche differences among species. Other authors have shown that high levels of stress or disturbance could lead to a general convergence in traits related to resource acquisition and to divergence in traits related to reproduction or 
defence (Grime \& Pierce 2012). Contrasting results in the literature indicate that interpreting patterns of trait dispersion is a challenging task that requires detailed system-specific knowledge (Mayfield \& Levine 2010; Kraft et al. 2015). However, observational data of trait clustering/dispersion remain useful to interpret underlying environmental conditions that influence community assembly (Cadotte \& Tucker 2017).

Accordingly, analysing groups with complex life cycles (like amphibians) from a trait-based approach could offer appropriate animal models for disentangling ecological factors that drive community assembly. Since there is evidence of uncoupling of phenotypic traits across life stages in amphibians (Sherratt et al. 2017; Wollenberg Valero et al. 2017), these animals provide the opportunity to explore whether response trait syndromes involve combinations of traits from different life stages. Moreover, due to their biphasic life cycle amphibians depend on changes occurring in contrasting environments. Particularly, the whole-life cycle of pond-breeding amphibians depends on both pond characteristics and local characteristics of the terrestrial habitat surrounding ponds. Species ability to develop, metamorphose and reproduce across water permanence gradients (i.e. from permanent to ephemeral) depends on larval development times and ability of adults to tolerate dry periods, optimize growth and time reproduction according to water pulses (Newman 1989, 1992; Dayton \& Fitzgerald 2011; Fabrezi 2011; Edge et al. 2016). In addition, canopy cover around ponds affects tadpole larval growth and development through changes in primary productivity and food availability, and represents a key structure for foraging, refuge and reproduction in adult stages (Skelly et al. 2002, 2014; Quesnelle et al. 2015; Rowland et al. 2016; Villaseñor et al. 2017). Constraints imposed by these simultaneous gradients of water and vegetation availability, may determine different response trait syndromes (e.g. a fast development of tadpoles together with fossorial habits in adults may be beneficial in ephemeral ponds). Consequently, patterns of trait dispersion in amphibian communities should vary across these pond environmental gradients, offering insights about the ecological processes that underlie community assembly.

Despite the potential offered by studying amphibian to elucidate community assembly, only few papers have addressed the study of amphibian communities from a functional trait-based approach (Joly \& Morand 1994; Ernst et al. 2006; Strauß et al. 2010; Ernst et al. 2012; Queiroz et al. 2015; Schalk et al. 2015; Strauß et al. 2016; Riemann et al. 2017). In this study, we test whether community assembly of pond-breeding amphibians is influenced by variations in hydroperiod and canopy cover through a functional trait-based approach. We test for associations between functional traits and pond hydroperiod and canopy cover gradients in amphibian communities from the Chaco ecoregion. Then we test whether these gradients influence functional structure of amphibian communities by analysing patterns of functional diversity. Based on the general theoretical frame, which postulates that environmental filtering increases trait convergence at sites with environmental constraints, we expect that functional diversity will decrease in ponds that are increasingly ephemeral and have reduced tree cover.

\section{MATERIALS AND METHODS}

\section{Study area}

The study was conducted in a region of $13400 \mathrm{~km}^{2}$ located in the southernmost and driest portion of the South American Chaco ecoregion (the Arid Chaco subregion) (coordinates: $29^{\circ} 29^{\prime} 1.22^{\prime \prime} \mathrm{S}$; $64^{\circ} 17^{\prime} 55.68^{\prime \prime} \mathrm{W}$ for the northernmost surveyed pond and $31^{\circ} 35^{\prime} 37.72^{\prime \prime} \mathrm{S} ; 65^{\circ} 22^{\prime} 52.93^{\prime \prime} \mathrm{W}$ for the southernmost surveyed pond) (Morello et al. 1985). The vegetation consists of a mosaic of xeric forest with a variable tree canopy cover (40-90\%) dominated by Aspidosperma quebracho-blanco. Forests alternate with natural halophytic scrublands and secondary scrublands resulting from forest degradation (Morello et al. 1985; Hoyos et al. 2012). The climate is subtropical, with a mean annual temperature of $19.9^{\circ} \mathrm{C}$ and maximum absolute temperatures that reach $47^{\circ} \mathrm{C}$. Rainfall is concentrated in the warm season (October to April) and is approximately $450 \mathrm{~mm} \mathrm{year}^{-1}$ (Morello et al. 1985).

\section{Pond selection and environmental gradients}

Thirty-nine temporary ponds were selected. Temporary ponds had highly variable hydroperiods and were located along a marked gradient of plant cover changes; thus, pond environments ranged from open, treeless sites to forest sectors with high tree cover on the pond margins. Therefore, we were able to cover full variation in hydroperiod and tree canopy cover of Arid Chaco ponds. Of the 39 ponds analysed, 25 were semi-natural water bodies. Natural ponds are scarce and usually ephemeral in the Arid Chaco; hence, small livestock producers in the area excavate around already existing water bodies to have more stable ponds to water livestock during the dry season. Both natural and semi-natural (farm ponds) are filled with summer rainwater and show similar arboreal and shrubby covers, indicating that both pond types are physiognomically similar (Lescano 2013). The main difference between pond types is area and hydroperiod. Given that small livestock producers have been present in the region for almost four centuries, seminatural water bodies have existed for a long time and are currently an integral part of the local landscape. For this reason, these types of water body were included in the experimental design. It is important to point out that all the water bodies sampled are fishless ponds.

Pond depth was used as a proxy of hydroperiod, since there is a direct relationship between both variables in the 
study area (Lescano 2013). The depth of the water bodies was calculated as the difference between the edge and the bottom of a pond; this measurement was taken when ponds were completely dry. Depth of surveyed ponds varied between 15 and $250 \mathrm{~cm}$. The deepest ponds hold water during most of the wet season and in some cases until the end of winter (August); nevertheless, none of the sampled ponds holds water year-round. Very shallow ponds are ephemeral and hold water for periods of 10-30 days only during the wet season and after heavy rains. Therefore, ephemeral ponds undergo multiple drying out events during the wet season. Tree canopy cover was calculated in the field as the percentage of shoreline covered with trees, and was quantified by measuring crown projection on ponds margins.

Since other local variables may vary along the two pond environmental gradients of interest, three additional environmental descriptors were measured in field: pond area, marginal pond herbaceous cover and shrub cover. The area of small ponds (up to $100 \mathrm{~m}^{2}$ ) was calculated in the field by measuring the longest and widest axes of the pond and then applying the ellipse equation. The surface area of larger ponds was quantified using Google satellite images in Quantum GIS free software. Marginal herbaceous cover represented the percentage of shoreline covered with herbaceous vegetation and was visually estimated. Shrub cover was calculated as the percentage of shoreline cover with shrubs (visually estimated on pond margins). With the exception of two pairs of ponds that were separated from each other by $270 \mathrm{~m}$ and $315 \mathrm{~m}$, the remaining sampled ponds were at a minimum distance of $2 \mathrm{~km}$ from one another. The most distant ponds were at a straight-line distance of $256 \mathrm{~km}$. Habitat variables were not correlated (the highest correlation corresponded to hydroperiod and tree cover; however, the Pearson coefficient was low; $r=0.34$ ).

\section{Amphibian surveys}

Surveys were conducted during three consecutive wet seasons (between late spring and summer), which coincides with the activity period of amphibians in the study area
(J. N. Lescano, pers. obs.). Amphibians were surveyed from November 2008 to February 2009, from November 2009 to March 2010 and from November 2010 to March 2011. Most ponds $(n=32)$ were surveyed on three occasions (once a year), except for seven ponds, which were surveyed on two occasions in consecutive years. In all cases, samplings were conducted after rainfall events of more than $30 \mathrm{~mm}$, since most Chaco amphibians are explosive breeders (Schalk \& Saenz 2016) and fossorial species of the area are active only after a heavy rainfall (J. N. Lescano, pers. obs.). Abundance of amphibians was recorded by counting the number of individuals present on the pond surface, pond bank area and shoreline vegetation of each surveyed pond (visual encounter surveys at breeding sites) (Scott \& Woodward 1994). These data were used to calculate a mean abundance value for each species at each pond.

\section{Amphibian functional traits}

Seven functional traits related to major aspects of resource acquisition, resource use and life history strategies in amphibians were measured for each species in the study area: Snout-vent length (SVL), head width (HW), head length (HL), tibia-fibula/hindlimb ratio (TF/HL), reproductive potential $(\mathrm{RP})$, reproductive mode (RM) and larval total length/development time ratio (LG) (Table 1). SVL was used as a proxy of adult biomass. SVL, HL and HW are functional traits related to the diet of frogs, since size and type of prey that can be consumed by amphibians are influenced by skull shape and body size. Frogs with big heads and large body size are capable of consuming largebodied prey such as vertebrates, whereas smaller sized species with smaller head consume smaller prey and may be small-invertebrate specialists (Emerson 1985; Schalk et al. 2014). TF/HL was used as a quantitative proxy of habitat use. Low TF/HL values indicate a more fossorial lifestyle, whereas high ratios are found in more terrestrial and arboreal species (Emerson 1976; Gomes et al. 2009; Schalk et al. 2015). RP is the number of mature eggs that females have in the oviduct and represents a direct measure of species investment in reproduction. Reproductive mode (RM)

Table 1. Functional traits measured for the 12 amphibian species recorded in the study area

\begin{tabular}{|c|c|c|c|}
\hline Functional trait & $\begin{array}{l}\text { Functional } \\
\text { trait code }\end{array}$ & Trait definition & Related Function \\
\hline $\begin{array}{l}\text { Snout-vent length } \\
\text { of adults }\end{array}$ & SVL & $\begin{array}{l}\text { Maximum length (Snout-vent length) of } \\
\text { post-metamorphic stages. }\end{array}$ & Resource acquisition \\
\hline Head length & $\mathrm{HL}$ & Head length/SVL ratio. & Resource use and acquisition \\
\hline Head width & HW & Head width/SVL ratio. & Resource use and acquisition \\
\hline $\begin{array}{l}\text { Tibia-fibula relative } \\
\text { length }\end{array}$ & $\mathrm{TF} / \mathrm{HL}$ & Tibia-fibula/hindlimb length ratio. & Resource use \\
\hline $\begin{array}{l}\text { Reproductive } \\
\text { potential }\end{array}$ & $\mathrm{RP}$ & $\begin{array}{l}\text { Maximum number of mature eggs that females } \\
\text { of each species contain in its oviducts. }\end{array}$ & $\begin{array}{l}\text { Reproduction investment, life } \\
\text { history strategy }\end{array}$ \\
\hline Larval growth rate & LG & $\begin{array}{l}\text { Larval maximum total length at metamorphosis/ } \\
\text { development time (minimum number of days } \\
\text { to reach metamorphosis). }\end{array}$ & $\begin{array}{l}\text { Life history strategy, investment in } \\
\text { growth and development }\end{array}$ \\
\hline Reproductive mode & $\mathrm{RM}$ & $\begin{array}{l}\text { Reproductive mode of each species, following } \\
\text { Haddad \& Prado (2005) }\end{array}$ & $\begin{array}{l}\text { Reproduction investment, life } \\
\text { history strategy }\end{array}$ \\
\hline
\end{tabular}


is a combination of traits that includes oviposition site, ovum and clutch characteristics, development, size and stage of hatchlings and type of parental care, if any (Haddad \& Prado 2005). LG is the relationship between larval size at metamorphosis and the time they take to reach that stage. This trait represents the trade-off between metamorphosing at a large size or avoiding the risk of mortality by pond desiccation (Newman 1989).

Morphological traits of adult amphibians were measured in specimens from the study area belonging to the amphibian collection of Centro de Zoología Aplicada (F.C.E.FyN., Universidad Nacional de Córdoba, Argentina). All variables were measured in at least five adult specimens for each species. Values of RP of each species were obtained from published data (Perotti 1997) and by examining individuals collected from the study area. Reproductive modes were classified based on the categories proposed by Haddad and Prado (2005). Larval total length of each species was measured in the field in at least 10 tadpoles per species from different sites of the study area that were at stages previous to metamorphic climax (stages 39 to 41) (Gosner 1960). Larval development times of each species were obtained from the literature (Cei 1980; Fabrezi 2011) and from personal field data. The functional trait values of each species are available in Appendix S1.

\section{Data analyses}

To detect associations between functional traits and variations in hydroperiod and tree cover, two complementary methods to analyse trait-environment relationships were combined: RLQ ordination and a fourth-corner permutation analyses (Kleyer et al. 2012; Dray et al. 2014). RLQ analysis relates three matrices: a matrix $\mathrm{R}$ (environmental variables) against $Q$ (species functional traits) through $L$ (species abundance) by performing a double inertia analysis of matrices $\mathrm{R}$ and $\mathrm{Q}$, assuming that matrix $\mathrm{L}$ is the link between environmental variables and functional traits (Dray et al. 2014). The fourth-corner analysis tests for trait-environment relationships through permutation models that describe trait-environment associations and summarize the joint structure of the three matrices (Dray \& Legendre 2008; Dray et al. 2014). The fourth-corner method also combines matrices $\mathrm{R}, \mathrm{L}$ and $\mathrm{Q}$ into a single matrix that describes trait-environment associations and tests the relationship between one trait and one environmental variable at a time, allowing the evaluation of individual trait-environmental relationships (Dray et al. 2014). RLQ ordination and fourth-corner test were performed by following procedures suggested by Dray et al. (2014). Fourth-corner was performed by using a high number of repetitions (10 000), the model types 2 and 4 and adjusted p-values for multiple comparisons with $f d r$ method. RQL and fourth-corner analyses were performed in $\mathrm{R}$ software ( $\mathrm{R}$ Development Core Team, 2016) using ade 4 package (Dray \& Dufour 2007).

To take into account the eventual phylogenetic bias in trait values, we performed a test of phylogenetic signal. We use a phylogeny based on Pyron \& Wiens (2011) to generate a pruned phylogeny containing only the species present in the study area. This partial phylogeny was used to quantify the phylogenetic signal in traits with Abouheif's tests
(Pavoine et al. 2008). For this test, we used 999 MonteCarlo permutations. Phylogenetic analyses were conducted in $\mathrm{R}$ software ( $\mathrm{R}$ version 3.4.3, $\mathrm{R}$ Development Core Team 2017) using functions available in Geiger (Harmon et al. 2008), Picante (Kembel et al. 2010) and Adephylo (Jombart et al. 2010) packages.

To analyse variations in functional diversity of local communities in response to environmental gradients, different primary components of functional diversity were computed: functional richness (Fric), functional divergence (Fdiv) and functional dispersion (Fdis) (Villéger et al. 2008; Laliberté \& Legendre 2010). Functional trait values in the species pool constrain the range of functional diversity values possible (Villéger et al. 2008); therefore, the recommendations of Mason et al. (2013) were followed and the values of the different functional diversity indices (Fric, Fdiv and Fdis) were compared in relation to random expectation under a matrix-swap null model to obtain the standardized effect size (SES). Thus, the indices SES_Fric, SES_Fdiv and SES_Fdis were obtained, which represent measures of functional diversity that are independent of species richness (Mason et al. 2013). We used 999 randomizations in all null-model analyses. Functional diversity analyses were performed in $\mathrm{R}$ software (Development Core Team, 2016) using the FD (Laliberté et al. 2015) and Picante (Kembel et al. 2010) packages.

To evaluate the response of functional diversity indices (SES_Fric, SES_Fdiv and SES_Fdis) to pond environmental gradients, first a multivariate ordination of ponds according to their environmental variables was performed using principal component analyses (PCA). Then, principal components were correlated with environmental variables to identify their associations with the environmental gradients. Finally, simple regression analyses between functional diversity indices and principal components were performed.

\section{RESULTS}

Twelve species were recorded in the studied pond system (Table 2). Species richness in ponds varied from four to eight species, with an average richness of $5.03 \pm 1.06$ species per pond. RLQ and fourthcorner analyses revealed a global significant relationship between functional traits and pond variables (Monte-Carlo test for model type 2 and model type 4 respectively: $P=0.0002$ and $P=0.00712)$. The first and the second axes of RLQ accounted for a projected inertia of $93.9 \%$ and $3.2 \%$ respectively. The ordination by RLQ method showed that variations in the abundance of species with different functional traits values were associated with hydroperiod and tree cover gradients (Fig. 1).

The combination of RLQ and fourth-corner analysis indicates that the first RLQ axis for the environmental gradients (AxR1) was positively related to HL, HW and LG, and negatively related to TF/HL and RP (Fig. 2a). The first RLQ axis for trait associations (AxQ1) was negatively related to canopy cover and pond hydroperiod (Fig. 2a). The same 
Table 2. Amphibian species recorded in the surveyed ponds $(n=39)$ and their occurrence (proportion of sites with presence)

\begin{tabular}{lcc}
\hline Amphibians species & Abbreviation & Occurrence \\
\hline Leptodactylidae & & \\
Leptodactylus bufonius & $L B U$ & 1 \\
Leptodactylus mystacinus & LMY & 0.18 \\
Leptodactylus latrans & $L L$ & 0.05 \\
Physalaemus biligonigerus & $P B I$ & 0.54 \\
Pleurodema tucumanum & $P T U$ & 0.36 \\
Pleurodema nebulosum & $P N E$ & 0.10 \\
Pleurodema guayapae & $P G U$ & 0.49 \\
Bufonidae & & \\
$\quad$ Rhinella arenarum & $R A R$ & 0.87 \\
Rhinella schneideri & $R S C$ & 0.23 \\
Hylidae & & \\
Phyllomedusa sauvagii & $P S A$ & 0.64 \\
Ceratophryidae & & \\
Lepidobatrachus llanensis & LLA & 0.41 \\
Chacophrys pierottii & $C H P$ & 0.15 \\
\hline
\end{tabular}

significant relationships were obtained when using both model types 2 and 4 . Fourth-corner test showed significant associations between two pond variables (hydroperiod and canopy cover) and five of the seven functional traits measured. A summary of such relationships is showed in Figure 2b. Canopy cover was negatively related to HL, HW and LG. In contrast, this environmental variable was positively related to RP. Pond hydroperiod was negatively related to LG and HW and positively related to TF/HL. Significant positive phylogenetic signal (i.e. closely related taxa had more similar traits than expected by chance) was detected in three traits (HW, TF.HL and LG) (Fig. 2b, Appendix S2).

The two-first axes of the PCA explained $52.6 \%$ of variation in pond ordination according to environmental variables (Fig. 3). The first principal component explained $27.4 \%$ of variation and was positively related to pond hydroperiod and pond canopy cover (Pearson correlations $r=0.81, \quad P<0.001$ and $r=0.72 ; P<0.001$ respectively). The second principal component explained $25.2 \%$ of variation and was negatively related to pond area and positively related to shrub cover (Pearson correlations $r=-0.62$, $P<0.001$ and $r=0.78 ; P<0.001$ respectively). The functional diversity index SES_Fdis was negatively related to the first principal component (i.e. variations in pond canopy cover and hydroperiod) $\left(\beta=-0.33, \quad t=-2.49 ; \quad P=0.0173, \quad r^{2}=0.14\right)$ (Fig. 4). Ponds with SES_Fdis index values lower than $-1.69(n=5)$ showed less functional divergence than expected by chance $(P<0.05)$ and had an average depth of $104 \mathrm{~cm}$ (SD $=51.3 \mathrm{~cm}$, range: 40 $150 \mathrm{~cm})$ and an average tree cover of $58 \%(\mathrm{SD}=13$, range $=40-70 \%$ ). The remaining functional diversity indices did not show significant relationships with the PCA axis.

Species richness showed a significant and positive relationship with the first principal component $\left(\beta=0.31, t=2.17 ; P=0.036, r^{2}=0.11\right)$. SES_Fdis and species richness were negatively correlated ( $r=-0.51, P=0.0009$ ) (Appendix S3). Ponds with less functional diversity than expected by chance had an average species richness of $5.8(\mathrm{SD}=0.84$, range: 5-7 species).

\section{DISCUSSION}

Most studies dealing with the relationship between amphibian assemblages and local environmental factors have focused on species composition and traditional diversity measures. Accordingly, although most empirical evidence suggests that pond hydroperiod and canopy cover are relevant in structuring pondbreeding amphibian communities, results are not always homogeneous and in some cases are contradictory across studies (see Welborn et al. 1996; Weyrauch \& Grubb 2004; Werner et al. 2007 and Semlitsch et al. 2015 for diversity responses to hydroperiod, and Skelly et al. 2014 and references therein for importance of canopy cover). According to our results, variations in hydroperiod and canopy cover of Chaco ponds constrain community assembly of pond-breeding amphibians via selection upon different combinations of functional traits. These changes in environmental constraints drive changes in patterns of trait dispersion, offering insights into the underlying ecological processes that shape community assembly of arid Chaco amphibians.

Although the relevance of hydroperiod for tadpole assemblages has been widely accepted (Welborn et al. 1996; Werner et al. 2007; Almeida-Gomes et al. 2016), our results suggest that hydroperiod of ponds might determine the structure of pond-breeding amphibian communities by conditioning both, larval and adult functional traits (Figs 1 and 2b). According to our results, ponds with short hydroperiod lead to an overall strategy involving specializations in resource use and life history (i.e. fossorial species with rapid development rates, represented by low values of TF/HL ratio and high values of LG respectively). In the study area, many of the species associated with ephemeral ponds exhibited high TF/ HL values (i.e. fossorial species) and, at the same time, their populations occur very close to bodies of water (L. llanensis, Ch. pierottii, P. nebulosum, P. guayapae) (Lescano 2013). Both characteristics have been mentioned as recurrent adaptations in anurans from arid environments (Blair 1976) and would be of particular importance for those species associated to ephemeral ponds in Chaco, because 


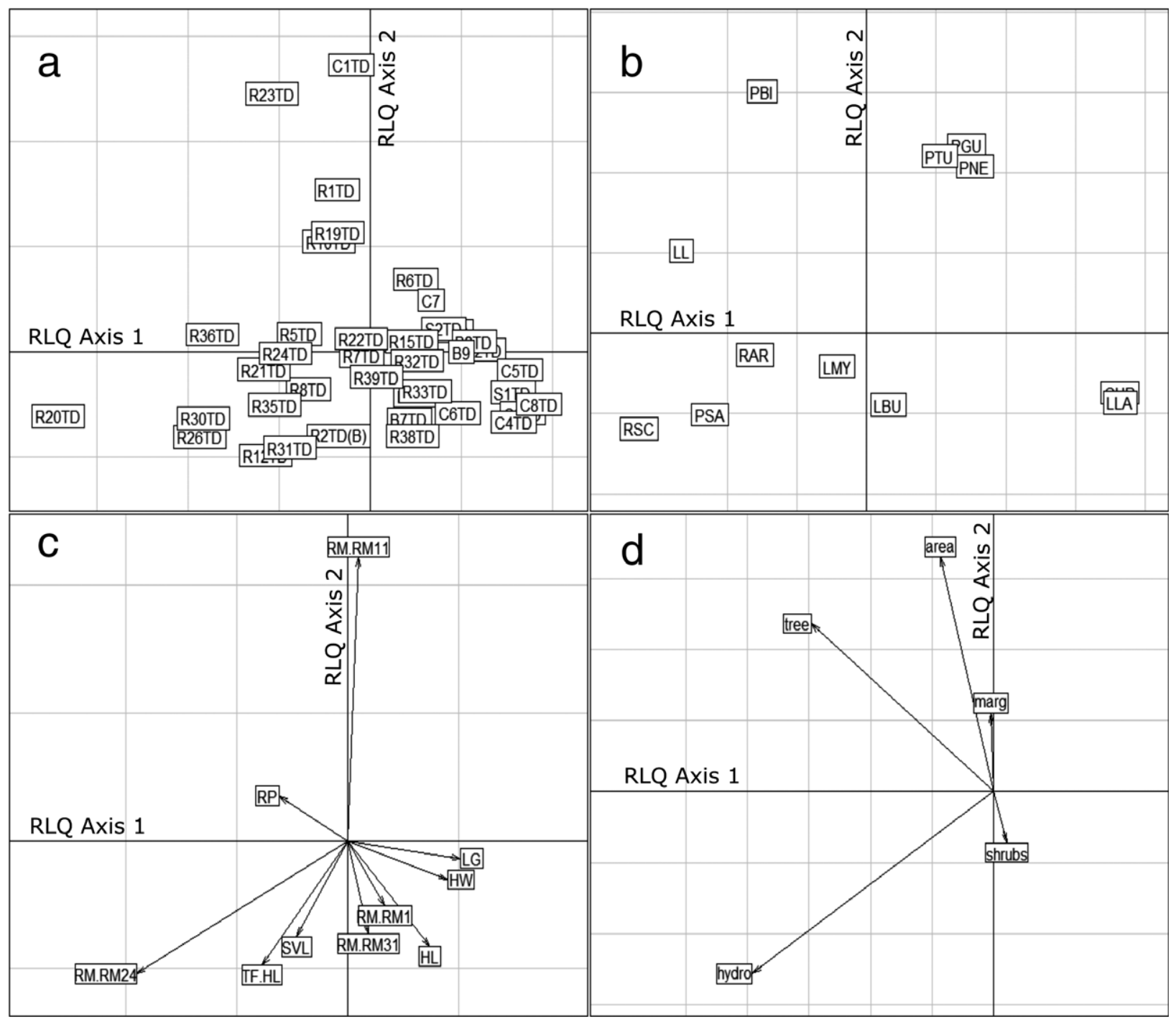

Fig. 1. RLQ scores along the first two axes for: (a) surveyed ponds, (b) species abundance, (c) amphibian functional traits and (d) environmental variables. Environmental variables abbreviations; area: pond surface; hydro: pond hydroperiod; marg: herbaceous marginal cover; shrubs: shrubs cover; trees: canopy cover. See Tables 1 and 2 for functional trait codes and species abbreviations respectively.

they allow individuals to cope with unpredictable droughts by burying at those sites that become flooded during rain events and that are used in explosive reproduction events. The relationship between the TF/HL functional trait and pond hydroperiod reported in the present work agree with Schalk et al. (2015), who suggested that the analysis of the fossoriality distribution and its relationship with environment could serve as a useful metric to understand the structure of local anuran assemblages. However, there may be other factors not considered in the analyses that might explain these associations. For example edaphic gradients are important for the occurrence of different amphibian life forms in other arid environments (Dayton et al. 2004; Schalk et al.
2015); at the same time, those edaphic variations may restrain pond permanence. We cannot discard the possible associations between edaphic variables and the values of traits related to fossoriality, however, if such association exists, then the relationship between hydroperiod and fossorial forms in the system may be indirect.

The relationship between hydroperiod and larval total length/development time ratio highlights the importance of larval development traits in driving community structure along the hydroperiod gradient (Fig. 1). Species associated with ephemeral pools share a strategy that involves reaching large sizes in very short times. This is a common strategy in amphibians from arid environments, since tadpoles 

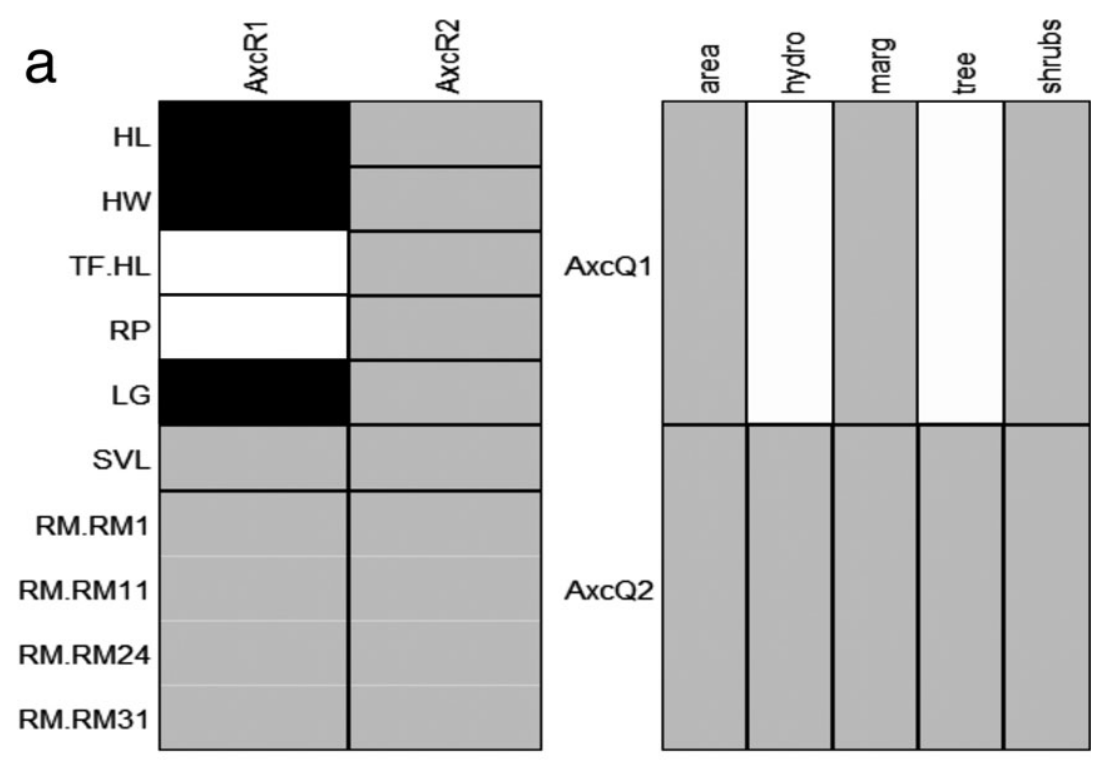

b

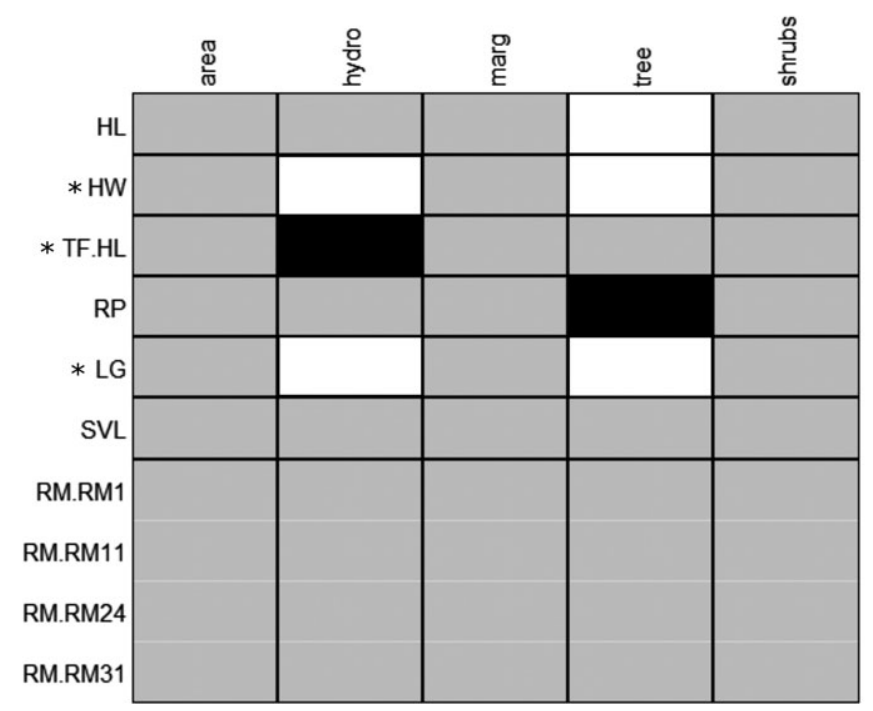

Fig. 2. (a) Scheme representing the associations between the axes obtained with the RLQ ordination method (AxcR and AxcQ), functional traits and environmental variables. The associations between the first two environmental axes (AxcR1 and AxcR2) and functional traits, and between the first two environmental axes (AxcQ1 and AxcQ2) and environmental variables, are represented. (b) Summarized results of fourth-corner test. Cells in grey represent non-significant associations. Positive and negative associations are represented in black and white respectively. *: Traits with phylogenetic signal according to Abouheif's tests. See Fig. 1 and Table 1 for pond variables and functional traits codes respectively.

in ephemeral ponds are usually exposed to a high risk of death by desiccation (Newman 1992). Although there are no published data on the temporal dynamics of ponds in the area, our field observations indicate that the average duration of shallow ponds (i.e. less than $25 \mathrm{~cm}$ ) is about 18 days (although duration partly depends on precipitation frequency). This time range is much lower than larval development time of many of the species present in the system (e.g. Leptodactlyus latrans; Leptodactylus mystacinus; Phyllomedusa sauvagii; Rhinella schneideri; Rhinella arenarum)
(Fabrezi 2011), explaining their absence (or their low abundance) in ephemeral pools. The association found between larval traits and different environmental variables agree with previous works showing importance of tadpole functional traits in understanding the influence of variations in wetland characteristics on anuran communities (Strauß et al. 2010; Queiroz et al. 2015).

Variations in tree cover were also related to the distribution of amphibian functional traits within the studied pond system. Larval growth rate, head 


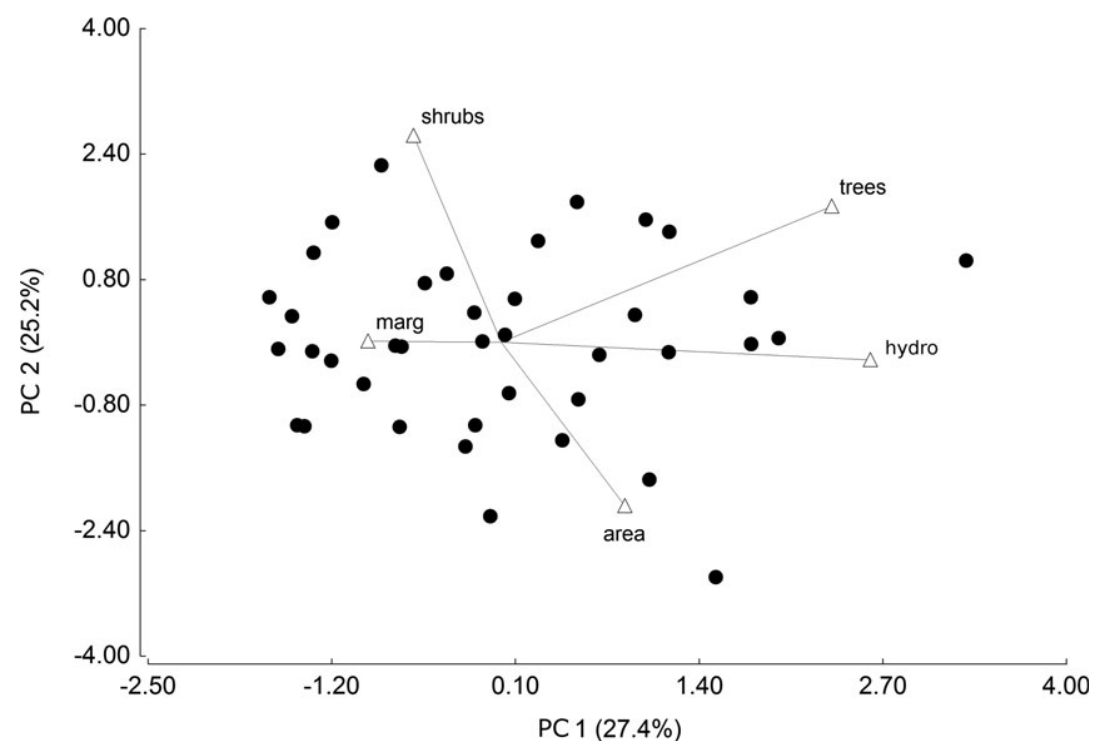

Fig. 3. Bi-plot showing the multivariate ordination of ponds according to environmental variables (Principal Component Analyses). PC1: First principal component, PC2: second principal component. Values in parentheses represent the variation explained for each principal component.

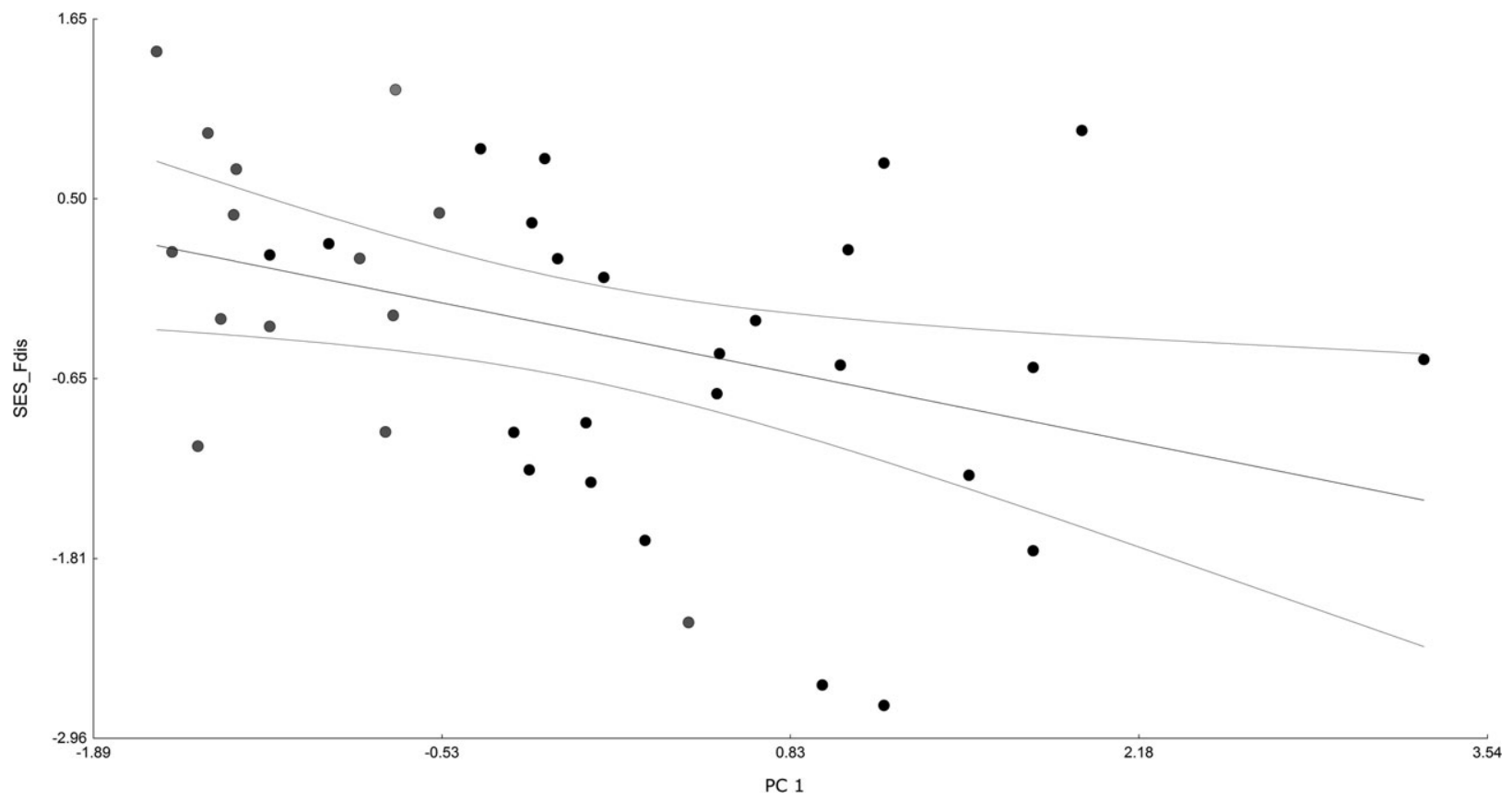

Fig. 4. Relationship between first principal component (PC1) (obtained through pond ordination according to habitat variables) and SES_Fdis index. 95\% confidence intervals are shown. Natural and semi-artificial ponds are represented by grey and black dots respectively.

length, head width and reproductive potential values were non-randomly distributed along the tree cover gradient (Figs 1 and 2b). Although the relationships between canopy cover and amphibian functional traits have been virtually unstudied in subtropical arid environments (but see Schalk et al. 2016), in temperate forests canopy cover negatively affects primary productivity and food availability, reducing tadpole larval growth and development rates (Skelly et al. 2014; Rowland et al. 2016). Low productivity of ponds could be important for amphibian assemblages in subtropical ephemeral ponds, since tadpoles with a fast development are highly mobile and need high temperatures and resources to reach 
metamorphosis in short periods (Newman 1992; Dayton \& Fitzgerald 2001). Therefore, it is likely that in the study area, those species of tadpoles with very fast development (10-15 days) are favoured in nonshaded ephemeral ponds. However, this ad hoc hypothesis should be confirmed via field or experimental studies.

Variation in reproductive potential and head length and width (functional traits related to reproduction investment and resource acquisition) along the tree cover gradient (Fig. 1) suggest that this environmental variable is also significant for the structure of anuran communities in the study area via a mechanism operating on functional traits of the adult stage. Although the response of adult functional traits to variation in tree cover has not been analysed in the context of amphibian community ecology, the changes in functional strategies involving traits related to resource acquisition and reproduction usually respond to productivity/stress gradients in other groups of organisms (Grime \& Pierce 2012; Díaz et al. 2015). Therefore, we highlight the need to address amphibian community studies considering interspecific variations in reproduction and diet in response to resource availability gradients.

An important aspect of our results is the coordinated response of traits from different stages to variations in pond characteristics (i.e. functional response syndromes involving larval and adult traits were identified). The use of traits related to different stages in animals with complex life cycles may be significant from a functional perspective, since if functional traits are selected properly (i.e. avoiding redundancy between traits), then any correlation between them may be considered a relevant aspect of species distribution in the multivariate functional trait space (Villéger et al. 2008). Therefore, we suggest that studies aimed to relate functional traits with environmental variables in animals with complex life cycles should be comprehensive and include traits related to different life stages.

It should be noted that closely related taxa showed similar values of some morphological and life history traits (Appendix S2, Fig. 2b). Although the existence of phylogenetic signal on these traits does not dismiss the ecological meaning of the associations detected with RLQ and fourth-corner methods, is worth to noting that this phylogenetic bias may implies a lack of independence in data used in correlative analyses. We recognize that ideally our analytical approach should have included a phylogenetic correction in the analyses that relate traits with environmental variables. At this point, we agree with Ernst et al. (2012) who have highlighted the need for an analytical procedure that includes phylogenetic information into trait-environmental relationships (Ernst et al., 2012).
Remarkably, shaded ponds with long hydroperiod supported amphibian communities with lower functional diversity values than expected by chance, whereas ponds with low tree cover and a short hydroperiod showed values of functional dispersion similar to those expected by chance (Fig. 4). These results were opposite to our predictions about functional diversity response. Although ephemeral ponds with few trees were associated with certain trait values that denote the existence of specializations to tolerate conditions prevailing at these sites (fossorial forms with larvae that metamorphose at a relatively large size and in a few days), these ponds are also inhabited by Leptodactylus bufonius: a non-fossorial species with tadpoles without fast development. Therefore, although ephemeral and open ponds present species-poor communities, dispersion of these species within the functional space is not different than expected by chance. Absence of non-fossorial species with slow development tadpoles in ephemeral and open ponds (with the exception of $L$. bufonius), suggests that environmental filtering shape amphibian communities in these ponds. Towards the other extreme of the gradients, the relative importance of constraints imposed by a very short hydroperiod is reduced, since ponds that retain water for more than two consecutive months potentially allows species in the system to reach metamorphosis. At the same time, constraints related to the absence of trees (such as the lack of habitat vertical stratification, the scarce availability of refuges and shade to withstand the climatic conditions prevailing in the system) also decrease. The dilution of these environmental constraints in shaded and stable ponds makes them suitable for several species that are similar in multiple traits (relatively long larval development, non-fossorial, with diets not specialized in large prey) (Fig. 1). Therefore, relaxation of certain environmental constraints enables the coexistence of functionally redundant species in stable and shaded ponds. As consequence these ponds shows high species richness, as well as lower functional diversity values than expected by chance (Fig. 4; Appendix S3). Is worth to noting that many of the stable ponds with high tree cover are semi-natural ponds. While these pond types favour amphibian species richness in the region (Lescano et al. 2015) the present results suggest that farm ponds shows high levels of functional redundancy. This result highlights the importance of these ponds in the area, since functional redundancy provides stability by acting as a buffer that ensure community resilience (Elmqvist et al. 2004).

Even though the negative relationship between functional diversity and species richness reported in this study (see Appendix S3) is apparently uncommon, this kind of response has been considered theoretically feasible (Mayfield et al. 2010). Moreover, 
low values of functional diversity observed in more stable and shaded ponds could indicate that competition may be a relevant assembly process in these ponds, since high level of competition could lead to trait-clustering patterns by selecting upon traits that maximize competitive ability (Mayfield \& Levine 2010). To understand to what extent combinations of traits observed in stable and shaded ponds confer an eventual competitive advantage deserves a deeper analysis in future studies. Finally, we encourage the use of trait-based perspectives to analyse amphibian communities, since our results indicate that a traitbased approach may represent a useful tool to understand amphibian's community assembly and their relationships with natural and human-based environmental changes.

\section{ACKNOWLEDGEMENTS}

We thank Christopher Schalk for valuable comments on an early draft of this manuscript. Three anonymous reviewers made valuable comments that improved the manuscript. This work was financially supported by Rufford Small Grant for Nature Conservation, MINCyT - PID 2010 (project 378 $\mathrm{n}^{\circ} 000113 / 2011$ ) and FONCYT (grant PICT $2013 \mathrm{~N}^{\circ}$ 1603). The animals were collected with a permit from Secretaría de Ambiente de la Provincia de Córdoba, Argentina.

\section{REFERENCES}

Almeida-Gomes M., Rocha C. F. D. \& Vieira M. V. (2016) Local and landscape factors driving the structure of tropical anuran communities: do ephemeral ponds have a nested pattern? Biotropica 48, 365-72.

Blair W. F. (1976) Adaptation of anurans to equivalent desert shrub of North and South America. In: Evolution of Desert Biota (ed D. W. Goodall) pp. 197-222. Texas Press, Austin.

Cadotte M. W. \& Tucker C. M. (2017) Should environmental filtering be abandoned? Trends Ecol. Evol. 32, 429-37 in press.

Cei J. M. (1980) Amphibians of Argentina. Monitore Zoologico Italiano, Torino.

Cornwell W. K., Schwilk D. W. \& Ackerly D. D. (2006) A trait-based test for habitat filtering: convex hull volume. Ecology 87, 1465-71.

Dayton G. H. \& Fitzgerald L. A. (2001) Competition, predation, and the distributions of four desert anurans. Oecologia 129, 430-5.

Dayton G. H. \& Fitzgerald L. A. (2011) The advantage of no defense: predation enhances cohort survival in a desert amphibian. Aquat. Ecol. 45, 325-33.

Dayton G. H., Jung R. E. \& Droege S. (2004) Large-scale habitat associations of four desert anurans in Big Bend National Park. Texas. F. Herpetol. 38, 619-27.
Díaz S. \& Cabido M. (2001) Vive la différence: plant functional diversity matters to ecosystem processes. Trends Ecol. Evol. 16, 646-55.

Díaz S., Kattge J., Cornelissen J. H. C. et al. (2015) The global spectrum of plant form and function. Nature 529, 1-17.

Dray S. \& Dufour A. B. (2007) The ade4 package: implementing the duality diagram for ecologists. F. Stat. Softw. 22, 1-20.

Dray S. \& Legendre P. (2008) Testing the species traitsenvironment relationships: the fourth-corner problem revisited. Ecology 89, 3400-12.

Dray S., Choler P., Dolédec S. et al. (2014) Combining the fourth-corner and the RLQ methods for assessing trait responses to environmental variation. Ecology 95, 14-21.

Edge C. B., Houlahan J. E., Jackson D. A. \& Fortin M. J. (2016) The response of amphibian larvae to environmental change is both consistent and variable. Oikos $125,1700-11$.

Elmqvist T., Folke C., Nystrom M. et al. (2004) Response diversity, ecosystem change, and resilience. Front. Ecol. 1, 488-94.

Emerson S. B. (1976) Burrowing in frogs. f. Morphol. 149, $437-58$

Emerson S. B. (1985) Skull shape in frogs: correlations with diet. Herpetologica 41, 177-88.

Ernst R., Keller A., Landburg G. et al. (2012) Common ancestry or environmental trait filters: Cross-continental comparisons of trait-habitat relationships in tropical anuran amphibian assemblages. Glob. Ecol. Biogeogr. 21, 704-15.

Ernst R., Linsenmair K. E. \& Rödel M. (2006) Diversity erosion beyond the species level: dramatic loss of functional diversity after selective logging in two tropical amphibian communities. Biol. Cons. 133, 143-55.

Fabrezi M. (2011) Heterochrony in growth and development in anurans from the Chaco of South America. Evol. Biol. 38, 390-411.

Flynn D. F. B., Gogol-Prokurat M., Nogeire T. et al. (2009) Loss of functional diversity under land use intensification across multiple taxa. Ecol. Lett. 12, 22-33.

Gomes F. R., Rezende E. L., Grizante M. B. \& Navas C. A. (2009) The evolution of jumping performance in anurans: morphological correlates and ecological implications. $\mathcal{F}$. Evol. Biol. 22, 1088-97.

Gosner K. L. (1960) A simplified table for staging Anuran embryos and larvae with notes on identification. Herpetologica 16, 183-90.

Grime J. P. (2006) Trait convergence and trait divergence in herbaceous plant communities: mechanisms and consequences. F. Veg. Sci. 17, 255-60.

Grime J. P. \& Pierce S. (2012) The Evolutionary Strategies that Shape Ecosystems. Wiley-Blackwell, Oxford.

Haddad C. F. B. \& Prado C. P. A. (2005) Reproductive modes in frogs and their unexpected diversity in the Atlantic forest of Brazil. Bioscience 55, 207.

Harmon L. J., Weir J. T., Brock C. D., Glor R. E. \& Challenger W. (2008) GEIGER: investigating evolutionary radiations. Bioinformatics 24, 129-31.

Hoyos L. E., Cingolani A. M., Zak M. R. et al. (2012) Deforestation and precipitation patterns in the arid Chaco forests of central Argentina. Appl. Veg. Sci. 16, 260-71.

Joly P. \& Morand A. (1994) Theoretical habitat templets, species traits, and species richness: amphibians in the Upper Rhône River and its floodplain. Freshw. Biol. 31, 455-68. 
Jombart T., Balloux F. \& Dray S. (2010) Adephylo: new tools for investigating the phylogenetic signal in biological traits. Bioinformatics 26, 1907-9.

Kembel S., Cowan P. D., Helmus M. R. et al. (2010) Picante: $\mathrm{R}$ tools for integrating phylogenies and ecology. Bioinformatics 26, 1463-4.

Kleyer M., Dray S., Bello F. et al. (2012) Assessing species and community functional responses to environmental gradients: which multivariate methods? f. Veg. Sci. 23, $805-21$.

Kraft N. J. B., Adler P. B., Godoy O., James E. C., Fuller S. \& Levine J. M. (2015) Community assembly, coexistence and the environmental filtering metaphor. Funct. Ecol. 29, 592-9.

Laliberté E. \& Legendre P. (2010) A distance-based framework for measuring functional diversity from multiple traits. Ecology 91, 299-305.

Laliberté E., Legendre P. \& Shipley B. (2015) Measuring functional diversity (FD) from multiple traits, and other tools for functional ecology. R Packag.

Lescano J. N. (2013) Patrones de Diversidad de Anfibios del Chaco Árido de la Provincia de Córdoba y sus Relaciones con el Paisaje y las Características Locales del Hábitat. PhD Thesis. Universidad Nacional de Córdoba, Córdoba, Argentina.

Lescano J. N., Bellis L. M., Hoyos L. E. \& Leynaud G. C. (2015) Amphibian assemblages in dry forests: multi-scale variables explain variations in species richness. Acta Oecologica 65-66, 41-50.

Maire V., Gross N., Börger L. et al. (2012) Habitat filtering and niche differentiation jointly explain species relative abundance within grassland communities along fertility and disturbance gradients. New Phytol. 196, 497-509.

Mason N. W. H. \& De Bello F. (2013) Functional diversity: a tool for answering challenging ecological questions. f. Veg. Sci. 24, 777-80.

Mason N. W. H., Irz P., Lanoiselée C. et al. (2008) Evidence that niche specialization explains species-energy relationships in lake fish communities. F. Anim. Ecol. 77, 285-96.

Mason N. W. H., De Bello F., Mouillot D., Pavoine S. \& Dray S. (2013) A guide for using functional diversity indices to reveal changes in assembly processes along ecological gradients. F. Veg. Sci. 24, 794-806.

Mayfield M. M. \& Levine J. M. (2010) Opposing effects of competitive exclusion on the phylogenetic structure of communities. Ecol. Lett. 13, 1085-93.

Mayfield M. M., Bonser S. P., Morgan J. W. et al. (2010) What does species richness tell us about functional trait diversity? Predictions and evidence for responses of species and functional trait diversity to land-use change. Glob. Ecol. Biogeogr. 19, 423-31.

McGill B. J., Enquist B. J., Weiher E. \& Westoby M. (2006) Rebuilding community ecology from functional traits. Trends Ecol. Evol. 21, 178-85.

Morello J., Protomastro J., Sancholuz L. \& Blanco C. (1985) Estudio macroecológico de los llanos de La Rioja. Serie del Cincuentenario la Administración de Parques Nacionales 5, 153.

Newman R. A. (1989) Developmental plasticity of Scaphiopus Couchii tadpoles in an unpredictable environment. Ecology 70, 1775-87.

Newman R. A. (1992) Adaptive plasticity in amphibian metamorphosis. What type of phenotypic variation is adaptive, and what are the costs of such plasticity? Bioscience 42, 671-8.

Perotti M. G. (1997) Modos reproductivos y variables reproductivas cuantitativas de un ensamble de anuros del Chaco semiárido, Salta, Argentina. Rev. Chilena Hist. Nat. 70, 277-88.

Pavoine S., Ollier S., Pontier D. \& Chessel D. (2008) Testing for phylogenetic signal in life history variables: Abouheif's test revisited. Theor. Popul. Biol. 73, 79-91.

Pyron A. R. \& Wiens J. J. (2011) A large-scale phylogeny of Amphibia including over 2800 species, and a revised classification of extant frogs, salamanders, and caecilians. Mol. Phylogenet. Evol. 61, 543-83.

Queiroz C., da Silva F. R. \& Rossa-Feres D. (2015) The relationship between pond habitat depth and functional tadpole diversity in an agricultural landscape. $R$. Soc. Open. Sci. 2, 150165.

Quesnelle P. E., Lindsay K. E. \& Fahrig L. (2015) Relative effects of landscape-scale wetland amount and landscape matrix quality on wetland vertebrates: a meta-analysis. Ecol. Appl. 25, 812-25.

$\mathrm{R}$ Developement Core Team (2016) R: A Language and Environment for Statistical Computing. R Foundation for Statistical Computing, Vienna, Austria. http://www. R-project.org/

Riemann J. C., Ndriantsoa S. H., Rödel M. \& Glos J. (2017) Functional diversity in a fragmented landscape: habitat alterations affect functional trait composition of frog assemblages in Madagascar. Glob. Ecol. Conserv. 10, 173-83.

Rowland F. E., Tuttle S. K., González M. J. \& Vanni M. J. (2016) Canopy cover and anurans: nutrients are the most important predictor of growth and development. Can. $\mathcal{F}$. Zool. 94, 225-32.

Schalk C. M. \& Saenz D. (2016) Environmental drivers of anuran calling phenology in a seasonal Neotropical ecosystem. Austral. Ecol. 41, 16-27.

Schalk C. M., Montaña C. G., Klemish J. L. \& Wild E. R. (2014) On the diet of the frogs of the Ceratophryidae: synopsis and new contributions. South. Am. F. Herpetol. 9, 90-105.

Schalk C. M., Montaña C. G. \& Springer L. (2015) Morphological diversity and community organization of desert anurans. F. Arid Environ. 122, 132-40.

Schalk C. M., Montaña C. G., Winemiller K. O. \& Fitzgerald L. A. (2016) Trophic plasticity, environmental gradients and food-web structure of tropical pond communities. Freshw. Biol. 62, 519-29.

Scott N. J. \& Woodward B. D. (1994) Surveys at breeding sites. In: Measuring and Monitoring Biological Diversity: Standard Methods for Amphibians (eds W. R. Heyer, M. A. Donnelly, R. W. McDiarmid, L. C. Hayek \& M. S. Foster) pp. 118-30. Smithsonian Institution Press, Washington.

Semlitsch R. D., Peterman W. E., Anderson T. L., Drake D. L. \& Ousterhout B. H. (2015) Intermediate pond sizes contain the highest density, richness, and diversity of pond-breeding amphibians. PLoS ONE 10, 1-20.

Sherratt E., Vidal-García M., Anstis M. \& Keogh J. S. (2017) Adult frogs and tadpoles have different macroevolutionary patterns across the Australian continent. Nat. Ecol. Evol. 1, 1385-91.

Skelly D. K., Freidenburg L. K. \& Kiesecker J. M. (2002) Forest canopy and the performance of larval amphibians. Ecology 83, 983-92. 
Skelly D. K., Bolden S. R. \& Freidenburg L. K. (2014) Experimental canopy removal enhances diversity of vernal pond amphibians. Ecol. Appl. 24, 340-5.

Spasojevic M. J. \& Suding K. N. (2012) Inferring community assembly mechanisms from functional diversity patterns: the importance of multiple assembly processes. F. Ecol. $100,652-61$.

Strauß A., Reeve E., Randrianiaina R.-D. et al. (2010) The world's richest tadpole communities show functional redundancy and low functional diversity: ecological data on Madagascar's stream-dwelling amphibian larvae. $B M C$ Ecol. 10, 1-12.

Strauß A., Guilhaumon F., Randrianiaina R. D. et al. (2016) Opposing patterns of seasonal change in functional and phylogenetic diversity of tadpole assemblages. PLoS ONE 11, e0151744.

Villaseñor N. R., Driscoll D. A., Gibbons P. et al. (2017) The relative importance of aquatic and terrestrial variables for frogs in an urbanizing landscape: key insights for sustainable urban development. Landsc. Urban Plan. 157, 26-35.

Villéger S., Mason N. W. H. \& Mouillot D. (2008) New multidimensional functional diversity indices for a multifaceted framwork in functional ecology. Ecology 89, 2290-301.

Violle C., Navas M. L., Vile D. et al. (2007) Let the concept of trait be functional!. Oikos 116, 882-92.

Webb C. T., Hoeting J. A., Ames G. M. et al. (2010) A structured and dynamic framework to advance traits-based theory and prediction in ecology. Ecol. Lett. 13, 267-83.

Weiher E. \& Keddy P. A. (1995) Assembly rules, null models, and trait dispersion: new questions from old patterns. Oikos 74, 159-64.

Weiher E., Freund D., Bunton T. et al. (2011) Advances, challenges and a developing synthesis of ecological community assembly theory. Philos. Trans. R. Soc. B Biol. Sci. 366, 2403-13.

Welborn G. A., Skelly D. K. \& Werner E. E. (1996) Mechanisms creating community structure across freshwater habitat gradient. Annu. Rev. Ecol. Syst. 27, 33763.

Werner E. E., Skelly D. K., Relyea R. A. \& Yurewicz K. L. (2007) Amphibian species richness across environmental gradients. Oikos 116, 1697-712.

Weyrauch S. L. \& Grubb T. C. (2004) Patch and landscape characteristics associated with the distribution of woodland Amphibians in an agricultural fragmented landscape: an information-theoretic approach. Biol. Cons. 115, 443-50.

Wollenberg Valero K. C., García-Porta J., Rodríguez A. et al. (2017) Transcriptomic and macroevolutionary evidence for phenotypic uncoupling between frog life history phases. Nat. Commun. 8, 15213.

\section{SUPPORTING INFORMATION}

Additional Supporting Information may be found in the online version of this article at the publisher's web-site:

Appendix S1. Functional traits values for each amphibian species from the study area.

Appendix S2. Results of the Abouheif's tests.

Appendix S3. Relationship between species richness and functional diversity. 